\title{
SARCOCYSTIS STRIXI N. SP. FROM A BARRED OWL (STRIX VARIA) DEFINITIVE HOST AND INTERFERON GAMMA GENE KNOCKOUT MICE AS EXPERIMENTAL INTERMEDIATE HOST
}

\author{
S. K. Verma*, A. Rosypal von Dohlen†, J. D. Mowerył, D. Scott $§$, C. K. Cerqueira-Cézar, B. M. Rosenthal`, J. P. Dubey ${ }^{\star}$, and \\ D. S. Lindsay $\|$ \\ * United States Department of Agriculture, Agricultural Research Service, Beltsville Agricultural Research Center, Animal Parasitic Diseases Laboratory, \\ Building 1001, Beltsville, Maryland 20705-2350. Correspondence should be sent to Jitender P. Dubey at: Jitender.Dubey@ars.usda.gov
}

\begin{abstract}
Here we report a new species of Sarcocystis with a barred owl (Strix varia) as the natural definitive host and interferon gamma gene knockout (KO) mice as an experimental intermediate host. A barred owl submitted to the Carolina Raptor Center, Huntersville, North Carolina, was euthanized because of paralysis. Fully sporulated $12.5 \times 9.9$ $\mu \mathrm{m}$ sporocysts were found in intestinal scrapings from the owl. Sporocysts from the barred owl were orally fed to 4 laboratory-reared outbred Swiss Webster (SW) (Mus musculus) and $8 \mathrm{KO}$ mice. All mice remained asymptomatic. Microscopic sarcocysts were found in all $5 \mathrm{KO}$ mice euthanized on day 32, 59, 120, 154, and 206 post-inoculation (PI), not in KO mice euthanized on day 4, 8, and 14 PI. Sarcocysts were not found in any SW mice euthanized on day 72 , 120, 206, and 210 PI. Sarcocysts were microscopic, up to $70 \mu \mathrm{m}$ wide. By light microscopy, the sarcocyst wall $<2 \mu \mathrm{m}$ thick had undulating, flat to conical, protrusions of varying dimensions. Numerous sarcocysts were seen in the histological sections of tongue and skeletal muscles from the abdomen, limbs, and eye but not in the heart. By transmission electron microscopy, the sarcocyst wall was "type $1 \mathrm{j}$." The ground substance layer (gs) was homogenous, up to $2 \mu \mathrm{m}$ thick, with very fine granules, and a few vesicles concentrated toward the villar projections. No microtubules were seen in the gs. Longitudinally cut bradyzoites at 206 days PI were $7.8 \times 2.2 \mu \mathrm{m}$. Based on molecular characterization using $18 S \mathrm{r} R N A, 28 \mathrm{~S} r R N A$, and $\operatorname{cox} 1$ genes and morphology of sarcocysts, the parasite in the present study was biologically and structurally different from species so far described, and we therefore propose a new species name, Sarcocystis strixi n. sp.
\end{abstract}

Sarcocystis species have a 2-host life cycle with asexual stages in extra-intestinal tissues (often herbivore) and sexual stages in the intestine (often carnivore). The definitive host becomes infected by ingesting infected tissues of the intermediate hosts containing mature sarcocysts. Bradyzoites released from sarcocysts penetrate into the lamina propria of the small intestine and undergo fertilization to form oocysts within a day. Oocysts sporulate in situ, and sporulated oocysts or sporocysts released from oocysts are excreted in feces. The intermediate host becomes infected by ingesting food and water contaminated with sporocysts. Sporozoites released from sporocysts initiate asexual multiplication, first as schizonts, and then as sarcocysts. Mature sarcocysts contain hundreds of bradyzoites. Bradyzoites are infectious only for the definitive hosts, and oocysts are infectious only for the intermediate hosts. Some Sarcocystis species, such as Sarcocystis muris and Sarcocystis spp. of lizards, can have a dihomoxenous life cycle where 1 host can act as both intermediate and definitive hosts (reviewed in Dubey et al., 2016).

Among the rodent-infecting Sarcocystis species using raptors as definitive hosts, barn owls (Tyo alba) are definitive hosts for

Received 1 December 2016; revised 27 July 2017; accepted 1 August 2017.

$\uparrow$ Department of Natural Sciences and Mathematics, Johnson C. Smith University, Charlotte, North Carolina 28216.

* United States Department of Agriculture, Agricultural Research Service, Beltsville Agricultural Research Center, Electron and Confocal Microscopy Unit, Building 12, Beltsville, Maryland 20705.

$\S$ Carolina Raptor Center, 6000 Sample Road, Huntersville, North Carolina 28078.

|l Department of Biomedical Sciences and Pathobiology, College of Veterinary Medicine, Faculty of Health Sciences, Virginia Tech, Blacksburg, Virginia 24061

DOI: $10.1645 / 16-173$
Sarcocystis dispersa (Cerná et al., 1978; Cerná, 1983) with the house mouse (Mus musculus) as intermediate host, while tawny owls (Strix aluco) are definitive hosts for Sarcocystis scotti of the house mouse (Munday, 1977; Levine and Tadros, 1980; Tadros and Laarman, 1980) and Sarcocystis sebeki of the field mouse (Apodmus sylvaticus) (Tadros and Laarman, 1976, 1982). Additionally, masked owls (Tyto novaehollandae) and barn owls ( $T$. alba) are reported definitive hosts for another Sarcocystis species present in the house mouse that was not described (Munday, 1977). A species of Sarcocystis has been reported from the northern saw-whet owl (Aegolius acadicus) and experimentally transmited to deer mice (Peromyscus maniculatus) (Espinosa et al., 1988). Sarcocystis rauschorum was described from snowy owls (Nyctea scandiaca) and experimentally cycled between varying lemmings (Dicrostonyx richardsoni) and snowy owls (Cawthorn et al., 1984; Cawthorn and Brooks, 1985). Sarcocystis species are generally considered host specific for the intermediate hosts (Dubey et al., 2016). For example, S. sebeki of the house mouse (Mus musculus) was not transmissible to field mice (Apodemus sylvaticus) or voles (Clethrionomys glareolus, Microtus arvalis) (Tadros and Laarman, 1982).

To our knowledge barred owls (Strix varia) are not known to be definitive hosts for Sarcocystis species. Here we identified barred owls as natural definitive hosts for a species of Sarcocystis infectious for the interferon gamma gene knockout (KO) mice but not for outbred Swiss Webster (SW) mice.

\section{MATERIALS AND METHODS}

\section{Naturally infected owl}

A barred owl (no. 19241) was admitted to the Carolina Raptor Center, Huntersville, North Carolina, for treatment on 2 
TABLE I. Experimental transmission of Sarcocystis strixi sporocysts from a barred owl into laboratory-reared mice.

\begin{tabular}{|c|c|c|c|c|}
\hline \multicolumn{2}{|l|}{ Mice } & \multirow{2}{*}{$\begin{array}{l}\text { Sporocysts } \\
\text { dose } \\
(\times 100)\end{array}$} & \multirow{2}{*}{$\begin{array}{c}\text { Days } \\
\text { post-inoculation }\end{array}$} & \multirow{2}{*}{$\begin{array}{l}\text { Sarcocysts } \\
\text { found }\end{array}$} \\
\hline Type & ID & & & \\
\hline \multirow{4}{*}{$\begin{array}{l}\text { Swiss Webster } \\
\text { mice }(\mathrm{SW})\end{array}$} & 750 & 420 & 210 & No \\
\hline & 746 & 420 & 206 & No \\
\hline & 965 & 42 & 120 & No \\
\hline & 966 & 42 & 72 & No \\
\hline \multirow{10}{*}{$\begin{array}{l}\text { Gamma interferon } \\
\text { gene knockout } \\
\text { mice }(\mathrm{KO})\end{array}$} & 744 & 420 & 206 & Yes \\
\hline & 743 & 420 & 154 & Yes \\
\hline & 745 & 420 & 32 & Yes \\
\hline & 967 & 42 & 120 & Yes \\
\hline & 969 & 42 & 59 & Yes \\
\hline & 968 & 42 & 14 & No \\
\hline & $474^{*}$ & 42 & 8 & No \\
\hline & 475 & 42 & 4 & No \\
\hline & 499 & Sub-passage* & 32 & No \\
\hline & 500 & Sub-passage* & 72 & No \\
\hline
\end{tabular}

* Sub-passage $=$ liver tissues of mice (ID 474) were homogenized in normal saline and inoculated subcutaneously into $2 \mathrm{KO}$ mice.

December 2015 from the town of Indian Trail located in Union County, North Carolina. The owl was not able to stand because of limb paralysis and was euthanized on the same day because it could not be rehabilitated and released. A necropsy was performed by DS. The intestinal tract was removed, placed in a plastic bag, and refrigerated at $4 \mathrm{C}$ until brought by motor vehicle to the Zoonotic Protozoal Diseases Laboratory (ZPDL), Center for Molecular Medicine and Infectious Diseases, Department of Biomedical Sciences and Pathobiology, Virginia-Maryland College of Veterinary Medicine, Virginia Tech, Blacksburg, Virginia, by ARD. The intestinal tract was opened using scissors, and smears were made from 3 different regions and examined by DSL using light microscope. After the identification of Sarcocystis oocysts and sporocysts, the intestinal mucosa was scraped off using a glass slide and scrapings placed in a sterile $50 \mathrm{ml}$ screw cap disposable test tube. Ten milliliters of commercial bleach was added to the test tube and then vigorously shaken by hand for 15 to $30 \mathrm{sec}$. After the bleach had been in contact with the intestinal scrapings for $10 \mathrm{~min}$, the $50 \mathrm{ml}$ tube was filled with Hanks' balanced salt solution (HBSS), and it was centrifuged at $800 \mathrm{~g}$ for $10 \mathrm{~min}$. The pellet was resuspended in $15 \mathrm{ml}$ HBSS in a sterile 15 $\mathrm{ml}$ screw cap disposable test tube and centrifuged for $10 \mathrm{~min}$. This was repeated 2 additional times and the pellet re-suspended in 2 $\mathrm{ml}$ HBSS and stored at $4 \mathrm{C}$ until used. Sporocysts were measured using a calibrated ocular micrometer.

\section{Experimental infection of mice}

Sporocysts were sent by DSL from ZPDL to the Animal Parasitic Diseases Laboratory (APDL), U.S. Department of Agriculture, Beltsville, Maryland, for further experimentation. At APDL, sporocysts were inoculated orally into 4 Swiss Webster (SW) mice and $8 \mathrm{KO}$ mice with a mouse feeding tube and then euthanized at various time intervals (Table I). Complete necropsies of mice were performed, and portions of heart, lung, spleen, tongue, eye, brain, kidney, liver, intestine, and muscles were fixed in $10 \%$ buffered neutral formalin. Fixed tissue samples were cut into sections $(2.5 \times 0.7 \mathrm{~cm})$ placed in cassettes, embedded in paraffin, and sectioned $5 \mu \mathrm{m}$ thick. Tissue sections were stained with hematoxylin and eosin (HE) and observed using light microscopy. Additionally, carcasses of SW and KO mice were homogenized in a blender, digested in acid pepsin, and aliquots of digests were examined microscopically for bradyzoites as previously described in detail (Dubey et al., 2016).

Finally, portions of skeletal muscle were fixed in $2.5 \%$ glutaraldehyde in sodium cacodylate buffer. Samples were postfixed in osmium tetraoxide and processed routinely for transmission electron microscopy. Sections stained with uranyl acetate and lead citrate were examined and imaged at $80 \mathrm{kV}$ with a Hitachi HT-7700 transmission electron microscope (Hitachi High Technologies America, Dallas, Texas).

\section{Cell culture}

African green monkey kidney (CV-1) cells (ATCC CCL-70, Manassas, Virginia) were grown in $25 \mathrm{~cm}^{2}$ cell culture flasks in RPMI 1640 cell culture medium (Mediatech, Manassas, Virginia) containing $100 \mathrm{IU}$ penicillin $/ \mathrm{ml}, 100 \mu \mathrm{g} / \mathrm{ml}$ streptomycin $/ \mathrm{ml}$, and $10 \%(\mathrm{v} / \mathrm{v})$ fetal bovine serum (FBS). Cells were maintained in the same medium except the concentration of FBS was $2 \%$. Living cell cultures were examined in $25 \mathrm{~cm}^{2}$ flasks using an inverted microscope equipped with phase-contrast optics (Zeiss Invertoskope, Thornwood, New York) for 60 days post-inoculation (PI) of parasites. Cell culture medium was replenished once or twice a week PI based on these observations.

Sporocysts: Sporocysts in $0.5 \mathrm{ml}$ of $37 \mathrm{C}$ HBSS were suspended in $0.5 \mathrm{ml}$ of $37 \mathrm{C}$ excystation solution $(1.5 \%(\mathrm{w} / \mathrm{v})$ sodium taurocholic acid and $0.5 \%$ trypsin (w/v) (Sigma Chemical Co., St. Louis, Missouri) in HBSS in a $15 \mathrm{ml}$ sterile test tube. Sterile $2 \mathrm{~mm}$ glass beads were added to the tube and vortexed for $10 \mathrm{sec}$, and then the mixture was incubated at $37 \mathrm{C}$ in a water bath for $2 \mathrm{hr}$. The excystation solution was washed off by repeated centrifugation in HBSS and the pellet used to inoculate in $4\left(25 \mathrm{~cm}^{2}\right)$ cell culture flasks containing CV-1 cells ( 2 flasks at $6 \mathrm{hr}$ and 2 flasks at $12 \mathrm{hr}$ ). The inoculation media was washed off cultures $2 \mathrm{hr}$ PI, and fresh maintenance medium was added.

Schizonts: Sarcocystis species with mice as intermediate hosts often complete schizogony exclusively in liver around the second week after infection (Dubey et al., 2016). Therefore, special attention was focused on livers of mice 8 days PI (Table I). For this, most $(90 \%)$ of the liver was fixed in formalin, and the entire liver was sliced $2 \mathrm{~mm}$ thick and all pieces embedded in paraffin for histological sectioning. The remainder of the liver was homogenized in saline with pestle and mortar, and the homogenate was inoculated subcutaneously into $2 \mathrm{KO}$ mice and seeded on to $\mathrm{CV}-1$ cells. The KO mice were observed for 32 and 72 days PI, necropsied, and studied histologically (Table I). The cell cultures were observed for 60 days PI for schizonts.

\section{DNA extractions and PCR amplification}

Individual sarcocysts isolated mechanically under light microscope were directly transferred into ATL buffer (Qiagen, Valencia, California). Genomic DNA from sarcocysts was extracted using DNeasy Blood and Tissue Kit (Qiagen) according to the manufacturer's instructions. DNA quantification and quality were determined by Thermo Scientific NanoDrop Lite Spectrophotometer (Thermo Scientific, Waltham, Massachu- 
setts). PCR amplification and sequencing were done at 2 nuclear ribosomal DNA units, $18 S r R N A$ and $28 S r R N A$, and the mitochondrial cytochrome c oxidase subunit $1(\operatorname{cox} 1)$ locus. The complete regions of $18 S r R N A$ and $28 S r R N A$ were amplified using overlapping fragments and primer pairs: ERIB1/S2r, S5f/ S4r, S3f/Primer Bsarc, and KL1/LS2R, LS1F/KL3, respectively, as described previously (Gjerde and Josefsen, 2015). In addition, the partial sequence of coxl locus was amplified using primer pair SF1/SR5 (Gjerde and Josefsen, 2015). The PCR amplifications were performed in $50 \mu$ total reaction volume containing $10 \mathrm{pmol}$ of each primer and $1 \times$ Taq PCR Master Mix Kit (Qiagen). The thermal cycler (Veriti ${ }^{\circledR}$ Thermal Cycler, Applied Biosystems, Foster City, California) conditions were set at initial denaturation at $95 \mathrm{C}$ for $10 \mathrm{~min}$; 40 cycles of amplification ( $95 \mathrm{C}$ for $45 \mathrm{sec}, 52$ $56 \mathrm{C}$ for $45 \mathrm{sec}$, and $72 \mathrm{C}$ for $1 \mathrm{~min}$ ) and final extension at $72 \mathrm{C}$ for $10 \mathrm{~min}$. Both the positive (DNA from Sarcocystis neurona isolate) and the negative $\left(\mathrm{H}_{2} \mathrm{O}\right)$ controls were included in all the batches respectively. The amplified PCR products were run on $2.5 \%(\mathrm{w} / \mathrm{v})$ agarose gel with ethidium bromide stain and visualized by using Gel Logic 212 Imaging Systems (Eastman Kodak Company, Rochester, New York).

\section{DNA sequencing and phylogenetic analysis}

The PCR amplicons of $18 S$ rRNA, 28S rRNA, and coxl were excised from the gel and purified using QIAquick Gel Extraction (Qiagen) according to the manufacturer's recommendation. The purified PCR products were sent to Macrogen Corporation (Rockville, Maryland) for direct sequencing using the amplification primers, and sequenced in both forward and reverse. The resulting sequences were imported, read, edited manually if necessary, and analyzed using the software Geneious version 9.0.4 (Biomatters, Auckland, New Zealand). New sequences were compared with other sequences deposited in NCBI GenBank by BLASTn analysis to detect intra-species and interspecies variation on these DNA regions.

To discern the relationship of Sarcocystis strixi to other species of Sarcocystis, we reconstructed the phylogeny of its $18 S \mathrm{rRNA}$ with reference to other related sequences derived from GenBank subsequent to a BLAST search of the non-redundant nucleotide database. A multiple sequence alignment was generated by MUSCLE as implemented in Geneious v. 7.0, and phylogenetic relationships were reconstructed under the criterion of maximum likelihood, using a model chosen (among 24 alternatives) on the basis of the Bayesian Information Criterion using the model choice tool implemented in MEGA6. The selected model (Tamura-Nei $93+\mathrm{G}+\mathrm{I}$ ) modeled variability as gamma distributed with a shape parameter $=0.38$ and assumed $73 \%$ of sites to be invariant. PhyML, as implemented in Geneious 7.0, was used to reconstruct relationships from this alignment and using this model on 100 bootrstrap replicates of the data (Guindon et al., 2010).

\section{RESULTS}

\section{Sporocysts}

Fully sporulated sporocysts were found in intestinal scrapings of the barred owl (Fig. 1A). They measured $12.5 \times 9.9 \mu \mathrm{m}(11.2-$ $13.7 \times 8.8-10.9, \mathrm{n}=15)$ in size. Each sporocyst contained 4 elongated $7.5-8.5 \times 2-2.3 \mu \mathrm{m}$ sporozoites and a residual body. A Stieda body was not present in sporocysts (Fig. 1A).

\section{Schizonts}

Schizonts were not seen in tissues of any of the KO mice (Table I). However, in the KO mouse euthanized on 8 days PI there were multifocal areas of inflammation throughout the liver. No developmental stages of Sarcocystis were observed in inoculated CV-1 cell cultures during the 60 days of observation in both excysted sporozoites and liver homogenate of infected mice.

\section{Sarcocysts}

Many sarcocysts were seen in the muscles of $\mathrm{KO}$ mice euthanized on day 32, 59, 120, 154, and 206 PI (Fig. 1B-F). Sarcocysts were not found in any SW mice euthanized on day 72 , 120,206 , and $210 \mathrm{PI}$, and in $\mathrm{KO}$ mice euthanized on day 4, 8 , and 14 PI (Table I). Neither precystic schizogonic stages nor sarcocysts was found in sub-passage $\mathrm{KO}$ mice euthanized on day 32 and 72 PI (Table I). The sarcocysts were not grossly visible and were up to $70 \mu \mathrm{m}$ wide; the length could not be measured accurately because sarcocysts were twisted in myocytes. The sarcocyst wall had undulating flat to conical protrusions of varying dimensions under a light microscope. The wall varied in width $(<1$ to $2 \mu \mathrm{m}$ thick), depending on the area (Fig. 1C). In sections stained with HE, numerous sarcocysts were seen in sections of tongue and skeletal muscles from the abdomen, limbs, and eye (Fig. 1D-E). No sarcocysts was seen in the heart. In HE-stained sections the sarcocyst wall was eosinophilic and often without projections (Fig. 1F). Sarcocysts were partitioned by septa into compartments that contained metrocytes and bradyzoites at 32 days PI and bradyzoites at 206 days PI. Focal myositis was seen associated with degenerating sarcocysts (Fig. 1D, E). The inflammatory response consisted of mixed leukocytes. In the KO mouse at 32 days PI, free bradyzoites were seen apparently without the sarcocyst wall (Fig. 1G). Live bradyzoites were 7-8 $\mu \mathrm{m}$ long. In histological sections, bradyzoites were approximately $4 \mu \mathrm{m}$ long. Bradyzoites were not found in the pepsin digest of mice negative for sarcocysts by histological examination.

By TEM, the sarcocyst wall consisted of a highly undulating parasitophorous vacuolar membrane (pvm); the undulations were at irregular distances, up to $2.5 \mu \mathrm{m}$ apart from each other (Figs. 2, 3 ). The pvm was lined by an uneven electron dense layer (edl) that was up to $50 \mathrm{~nm}$ thick. The edl appeared denser at the tips of the fold (Fig. 3). The pvm was invaginated into the interior of the sarcocyst, and invaginations lacked edl at irregular distances, giving the appearance of pores in the wall (Fig. 3). The ground substance layer (gs) was homogenous with very fine granules and few vesicles vs. concentrated towards the villar projections. No microtubules were seen in villar projections. The gs was up to 2 $\mu \mathrm{m}$ thick and continued into the interior of the sarcocyst as septa (Figs. 2, 3). Metrocytes were $5 \mu \mathrm{m}$ in size with only a few organelles (Fig. 3). Longitudinally cut bradyzoites at day $206 \mathrm{PI}$ were $7.8 \times 2.2(7.1-8.4 \times 1.5-2.9 ; \mathrm{n}=25) \mu \mathrm{m}$ in size. Bradyzoites contained a conoid, and numerous irregularly arranged micronemes occupying the anterior of the bradyzoite. No more than 2 rhoptries were seen in any bradyzoite section (Fig. 3). There were several dense granules, amylopectin granules, and a sub-terminally located nucleus. The amylopectin granules were few and often located at the non-conoidal end. Both metrocytes and bradyzoites divided by endodyogeny. 


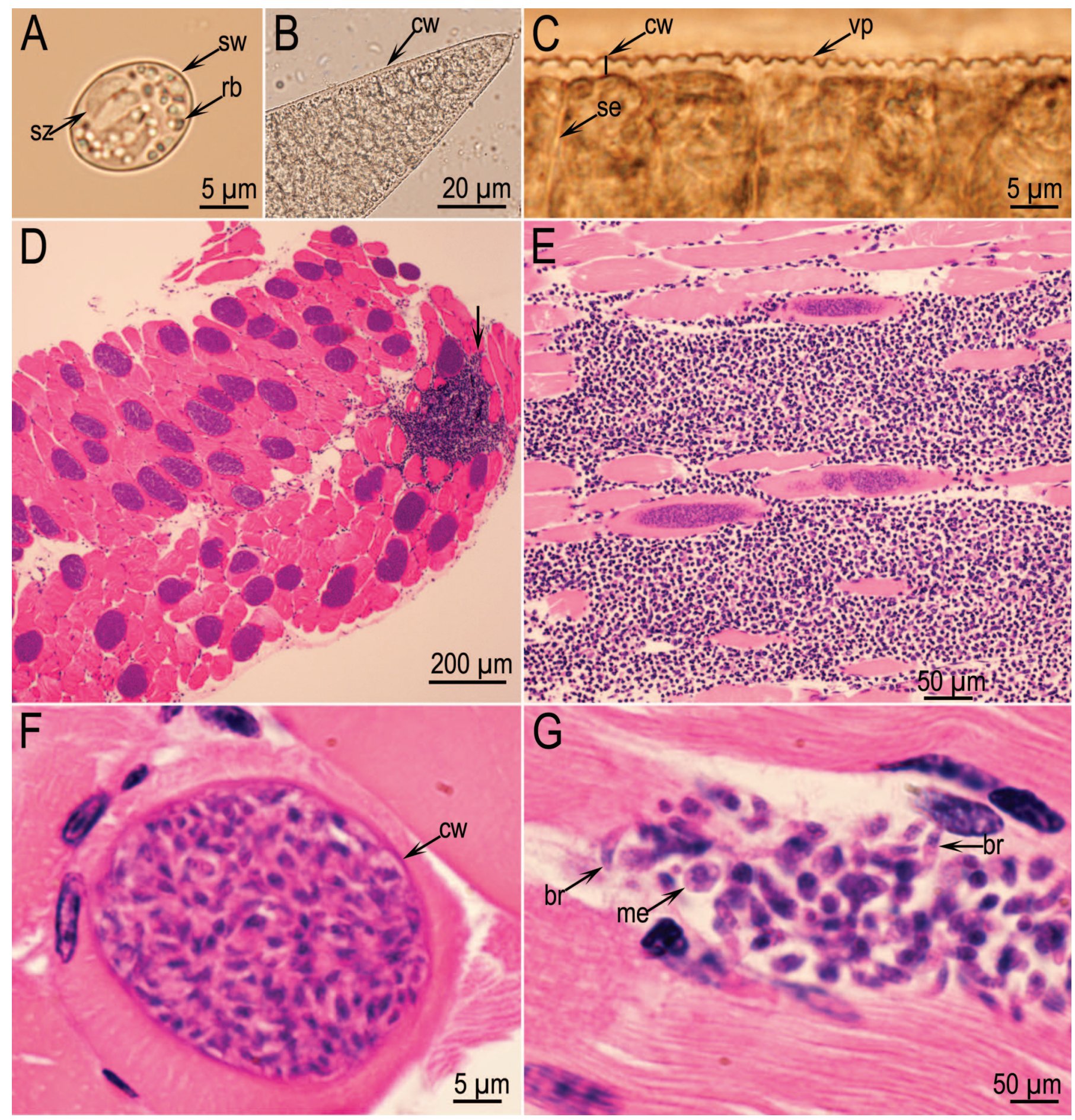

Figure 1. Life cycle stages of Sarcocystis strixi n. sp. (A) Sporocysts from the intestine of a naturally infected barred owl (Strix varia). Note thin sporocyst wall (sw), 4 elongated sporozoites (sz) and granules of the residual body (rb). (B) Microscopic mature sarcocyst isolated from the muscles of experimentally infected KO mice, 206 days PI, unstained. (C) Sarcocyst wall (cw) with villar protrusions (vp). Also note septa (se). (D) Numerous sarcocysts in abdominal muscle. Arrow points to an inflammatory focus. (E) Severe inflammatory response around sarcocysts in leg muscle. (F) Cross section of a mature sarcocyst with a thin sarcocyst wall, without any visible protrusions. (G) Bradyzoites (br) and metrocytes (me) apparently without a cyst wall. (C-F) Sarcocysts in experimentally infected KO mice, $\mathrm{C}-\mathrm{F}=206$ days PI. G $=32$ days PI. B, C-unstained, D- $\mathrm{G}=$ histological sections of muscle, stained with hematoxylin and eosin. Color version available online. 


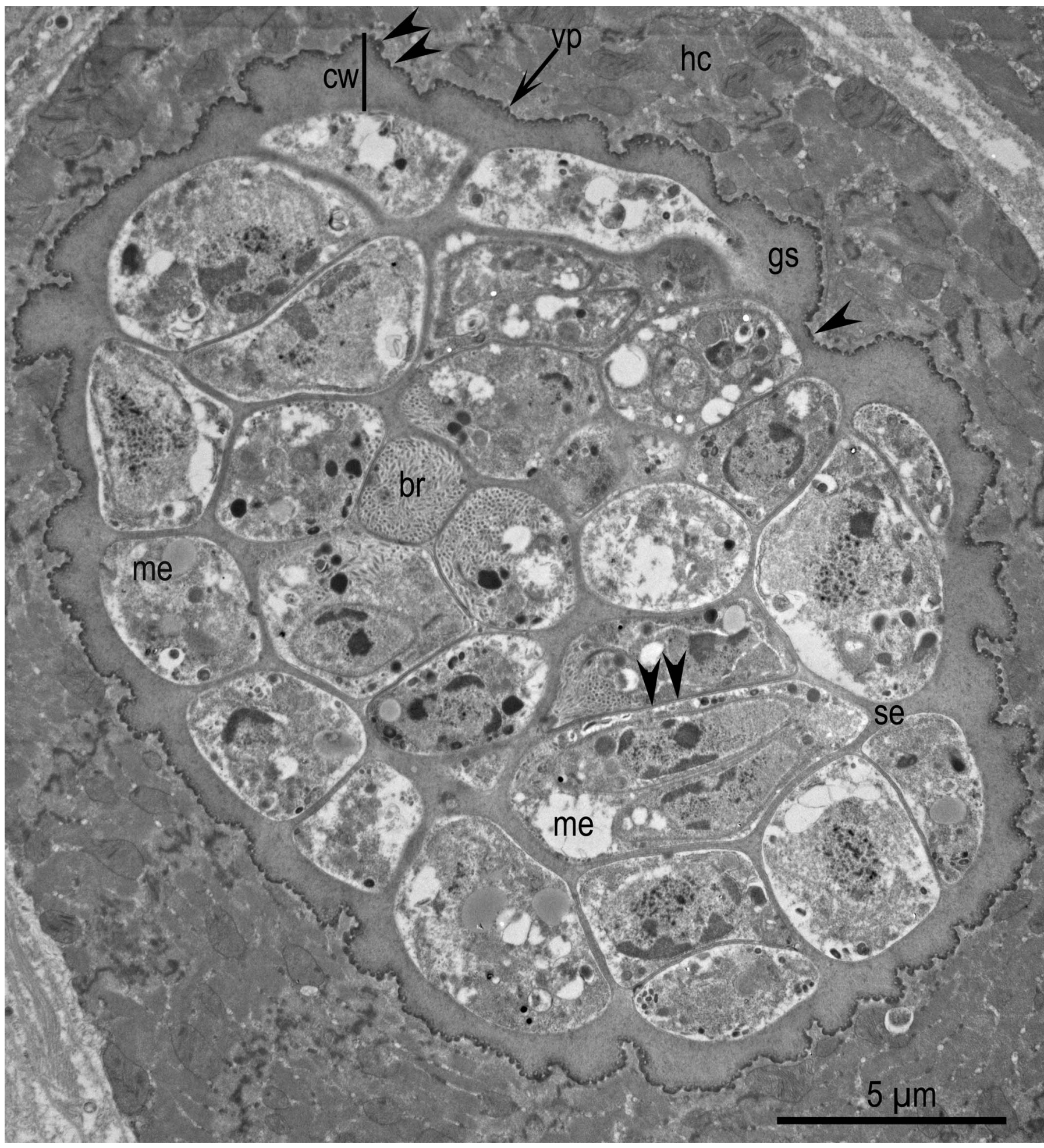

FIgURE 2. TEM of a Sarcocystis strixi $\mathrm{n}$. sp. sarcocyst in cross section, 32 days PI. The sarcocyst has undulating surface. Note variability in thickness (arrowheads) of the cyst wall (cw). The ground substance layer (gs) is smooth and continued in the interior of the sarcocyst as septa (se). Most organisms are metrocytes (me) and 1 is dividing by endodyogeny (double arrows). Also note 2 bradyzoites (br) and the host cell (hc). 


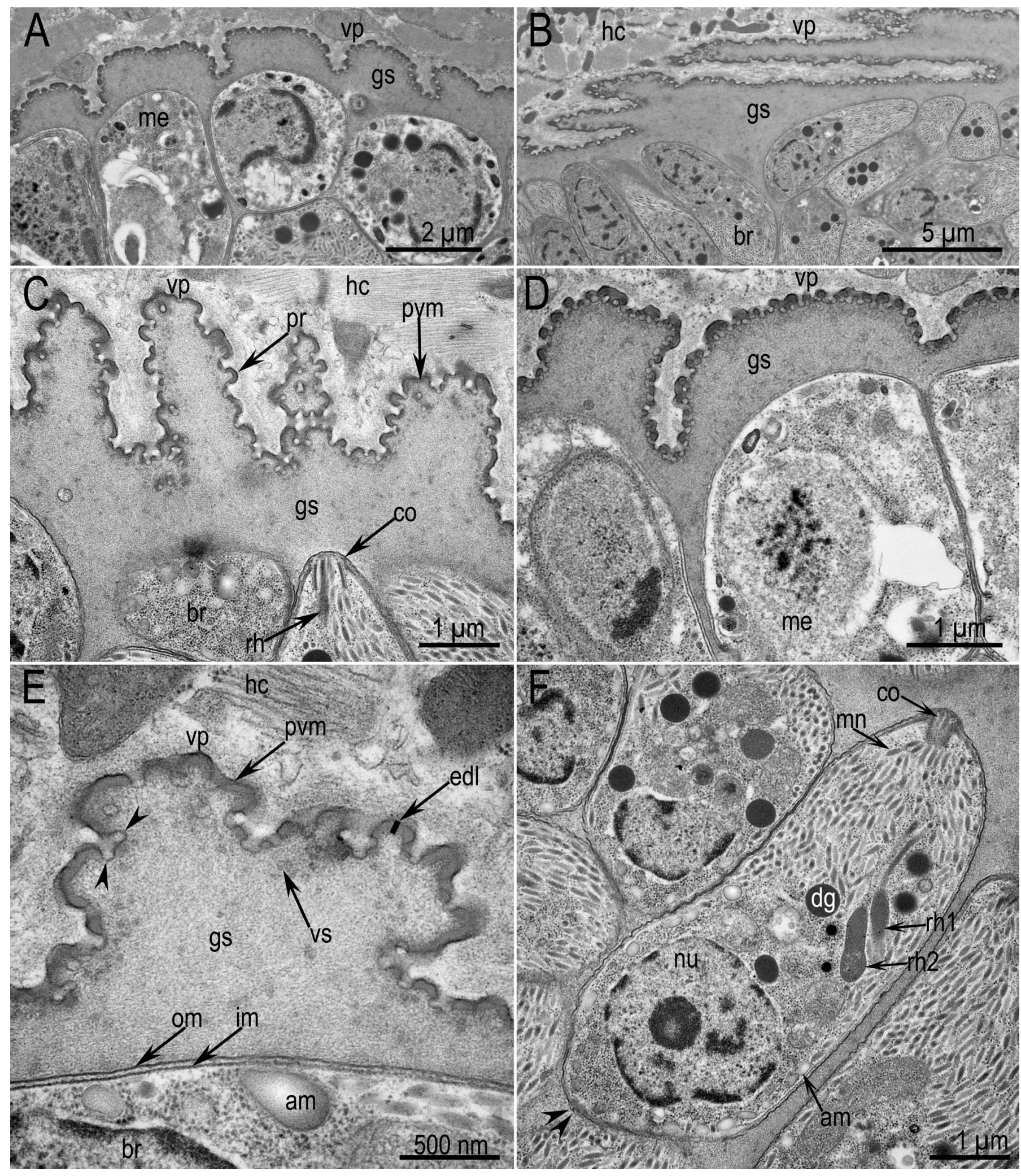

FIGURE 3. TEM of sarcocysts of Sarcocystis strixi n. sp. (A) Sarcocyst with relatively flat vp. (B) Sarcocyst with angular vp. (C) Note projections (pr) on vp. (D) Metrocyte, probably transforming to bradyzoite. (E) Details of vp. Note pvm lined by edl of uneven thickness, almost missing in areas of invaginations of the pvm in the gs (arrowheads). Also note the juxtaposition of a bradyzoite plasma lemma with outer (om) and inner membrane (im) and amylopectin granules (am). (F) Bradyzoite with a conoid (co), numerous micronemes (mn), 2 rhoptries (rh1, rh2), and posteriorly located nucleus (nu) and amylopectin granules ( $\mathrm{am}) . \mathrm{A}=32$ days PI, B-E $=206$ days PI. Note host cell (hc), parasitophorous vacuolar membrane (pvm) lined by electron dense layer (edl), villar protrusion (vp), ground substance layer (gs), vesicles (vs), metrocytes (me), and bradyzoites. Also note variability in the appearance of $v p$ in 5 images depicted here. 


\section{In vitro cultivation}

No developmental stages of Sarcocystis were observed in any of the 4 flasks of CV-1 cell cultures inoculated with sporozoites/ sporocysts or liver homogenates.

\section{PCR and DNA analysis}

Molecular analysis with sarcocysts DNA as the template yielded amplicons of the expected size for the $18 S \mathrm{rRNA}, 28 S \mathrm{rRNA}$, and cox1 loci. PCR-DNA sequencing of amplicons resulted the unambiguous sequences of 2 nuclear DNA regions; $18 S$ rRNA (1,782 bp), $28 S$ rRNA (1,493 bp), and the mitochondrial DNA locus, coxl (1,045 bp). These sequences were submitted to NCBI GenBank with accession numbers MF162315 (18S rRNA), MF162316 (28S rRNA), and MF162317 (coxl) and designated as $S$. strixi n. sp. Analysis of $18 S r R N A$ sequence obtained from $S$. strixi $n$. sp. confirmed its membership among the genus Sarcocystis and indicated an especially close relationship to other parasites in this genus that employs birds as their hosts: Sarcocystis corvusi (JN256117), Sarcocystis lari (JQ733508), Sarcocystis sp. ex Phalacrocorax carbo, Sarcocystis columbae (JQ733511), Sarcocystis sp. ex Columba livia (GQ245670.1), and Sarcocystis sp. ex Anser albifrons (EU502869).

Relationships among $18 S \mathrm{SRNA}$ sequences from various species of Sarcocystis were reconstructed to understand the evolutionary position of $S$. strixi with respect to its congeners. Almost complete identity with several other species at this slow-evolving molecule precluded complete resolution of this tree, but sufficed to identify $S$. strixi as a member of a clade containing several other parasites known or suspected to use raptors as definitive hosts and their avian and mammalian prey as intermediate hosts. Although phylogenetic information in this molecule is too limited to allow definitive conclusion, our results suggest that among sampled parasite taxa to date, the most closely related species to $S$. strixi may be $S$. dispersa, which completes its life cycle in another species of owl (the long-eared owl, Asio otus) (Fig. 4).

The partial $28 S r R N A$ sequence of $S$. strixi n. sp. shared $97 \%$ identity with sequences of Sarcocystis sp. ex Columba livia (FJ232949), Sarcocystis (Frenkelia) glareoli (AF044251), Sarcocystis (Frenkelia) microti (AF044252), Sarcocystis lutrae (KM657771, KM657772), Sarcocystis arctica (KX022104-7, KF601312), S. lari (JQ733509), Sarcocystis turdusi (JF975682) Sarcocystis sp. ex Accipiter nisus (GU253888), Sarcocystis calchasi (KU220951), and many other species of Sarcocystis.

The partial coxl sequence of $S$. strixi n. sp. (1,045 bp) shared 99\% identity with S. lutrae (KM657808, KF601326), S. turdusi (KT588511-KT588518), S. arctica (KX022112-KX022115, KF601318-KF601321), and Sarcocystis speeri (KT207461) and 98\% identity with Sarcocystis rileyi (KT184389, KJ396582) and S. neurona (KF854272).

\section{DESCRIPTION Sarcocystis strixi $\mathrm{n}$. sp. (Figs. 1-4)}

Diagnosis: Sporocysts in the intestine of barred owl, $12.5 \times 9.9$ $(11.2-13.7 \times 8.8-10.9, \mathrm{n}=15) \mu \mathrm{m}$ in size. Sarcocysts in KO mice microscopic, with thin $(<2 \mu \mathrm{m})$ sarcocyst wall with wavy outline and conical to flat projections. Ultrastructurally, the sarcocyst wall "type 1" with wavy parasitophorous vacuolar membrane lined by electron dense layer. Microtubules absent in villar projections of the pvm and in the smooth ground substance layer. Bradyzoites $7.84 \times 2.19 \mu \mathrm{m}$ in size.

\section{Taxonomic summary}

Type definitive host: Barred owl (Strix varia).

Natural intermediate host: Unknown.

Experimental intermediate host: Interferon gamma gene $\mathrm{KO}$ mouse.

Type locality: Indian Trail, Union County, North Carolina, USA.

Other localities: Unknown.

Etymology: Species named after the genus of the definitive host, barred owl (Strix varia).

Specimens deposited: Hematoxylin and eosin-stained histologic slides from the IFN- $\gamma$ gene KO mouse no. 744, Pathology no. D9065-2 (containing sarcocysts in skeletal muscle-USNM no. 1422354) has been cataloged at the National Parasite Collection housed at the Smithsonian Institution, National Museum of Natural History, Department of Invertebrate Zoology (USNM).

Sequences deposited: Sequences deposited in NCBI GenBank with accession numbers MF162315 (18S $r R N A)$, MF162316 (28S $r R N A)$, and MF162317 ( $\operatorname{cox} 1)$.

\section{Remarks}

Sarcocystis species are generally host-specific for the intermediate host, especially those using rodents as intermediate hosts (Dubey et al., 2016). The ultrastructure of the sarcocyst wall is a useful taxonomic criterion for differentiating Sarcocystis species within a given host. The sarcocyst wall of the species in the present study is structurally distinct from other species described. Dubey et al. (2016) proposed 42 types of sarcocyst walls with many subdivisions within some of the wall types. By light microscopy, sarcocysts were grouped as thin-walled $(<1 \mu \mathrm{m})$ or thick-walled $(>2 \mu \mathrm{m})$. The "type 1" sarcocyst wall is thin and has small blebs on the wall; it was subdivided into 8 subtypes $(1 \mathrm{a}-1 \mathrm{~h})$ depending on the villar protrusions (Dubey et al., 2016). To this description a new "type 1i" was added for Sarcocystis jamaicensis from red-tailed hawks (Verma et al., 2017). Type 1 sarcocyst wall has knoblike blebs with rounded ends. Here we have added another new type "type $1 \mathrm{j}$ " in the present study. In S. strixi n. sp., the undulations were at irregular distances, up to $2.5 \mu \mathrm{m}$ apart from each other. The pvm was invaginated into the interior of the sarcocyst, and invaginations lacked edl at irregular distances, giving the appearance of pores in the wall.

\section{DISCUSSION}

Based on the structure of sarcocysts, non-infectivity for house mice, and molecular characteristics, S. strixi n. sp. described in the present study is different from other Sarcocystis species from rodents that use raptors as definitive hosts. The structures of $S$. strixi $\mathrm{n}$. sp. sarcocysts in $\mathrm{KO}$ mice in the present study vaguely resemble those of $S$. sebeki from tawny owls (Strix aluco) in muscles of long-tailed field mice (Apodemus sylvaticus). There is considerable confusion and uncertainty regarding $S$. sebeki; its description is incomplete and spread over 3 reports by Tadros and Laarman $(1976,1978 b, 1979)$. This information is summarized 


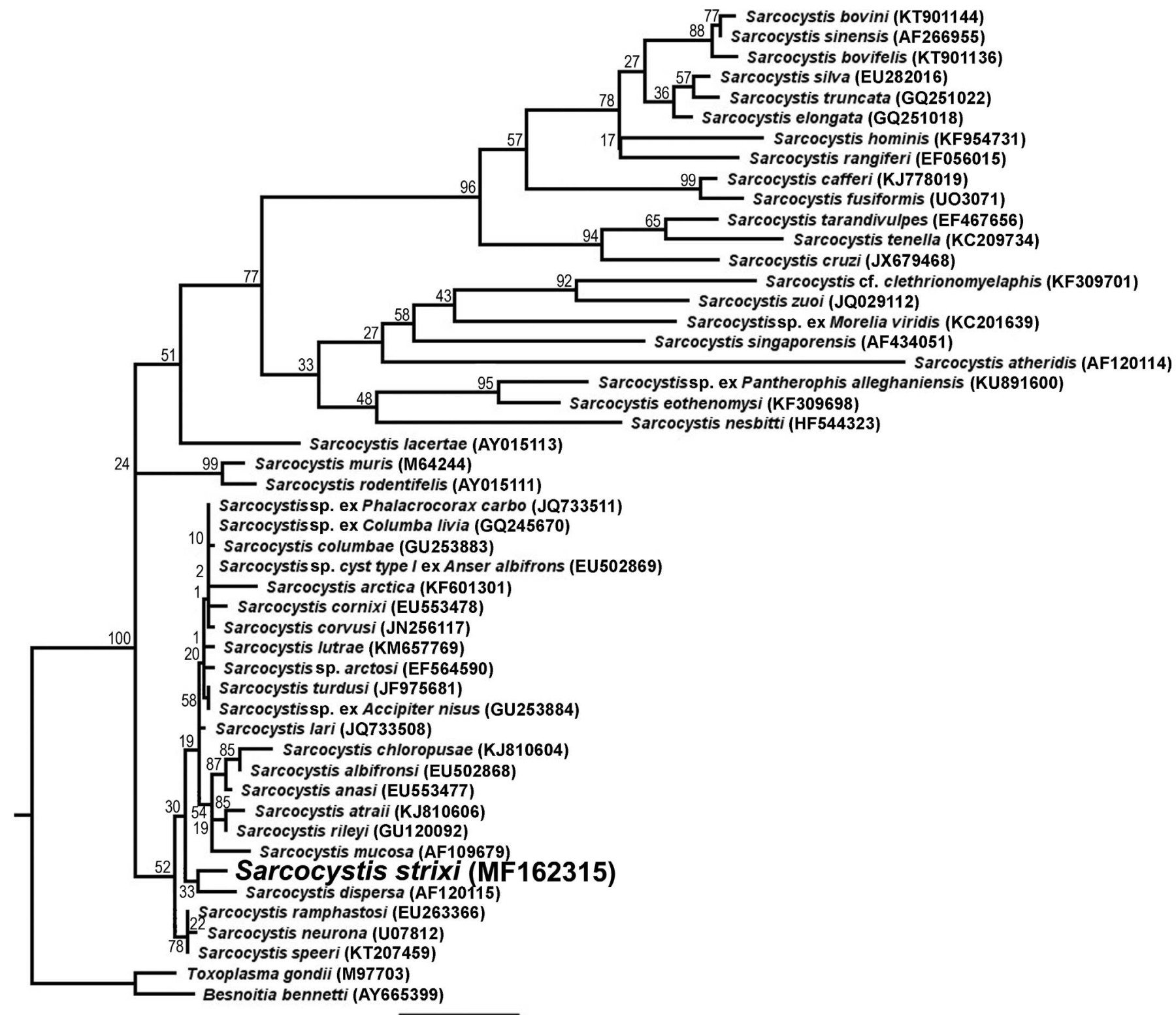

0.1

Figure 4. Phylogenetic tree based on $18 S \mathrm{r} R N A$ sequences was reconstructed under the criterion of maximum likelihood using Tamura-Nei $93+\mathrm{G}+$ I model of sequence evolution. Variability among sites was assumed to be gamma distributed with a shape parameter $=0.38$ and $73 \%$ of sites as invariant. PhyML, as implemented in Geneious 7.0, was used to reconstruct relationships from this alignment and using this model on 100 bootstrap replicates of the data (Guindon et al., 2010).

here for the benefit of future investigators. Sporocysts measuring $10 \times 14 \mu \mathrm{m}$ found in intestinal scrapings of a tawny owl (no. 1) in the Netherlands were fed to long-tail field mice (A. sylvaticus); the source and number of mice and the source of the owls were not reported. Macroscopic (several centimeters long sarcocysts) were found in skeletal muscle of 2 mice 3 mo later. Infected mouse tissues were fed to an adult tawny owl (no. 2) at the Artis Zoo in Amsterdam. Eight days later, the owl excreted sporocysts similar to those found in owl no. 1 (Tadros and Laarman, 1976). They provided a limited description of the ultrastructure of sarcocysts in a second paper (Tadros and Laarman, 1978a). By light microscopy, the sarcocyst wall was undulated but without projections. By TEM, the "outer unit membrane" was $6 \mathrm{~nm}$ thick and had $110 \mathrm{~nm}$ osmiophilic invaginations; bradyzoites or metrocytes were not described (Tadros and Laarman, 1978a). Subsequently, Tadros and Laarman (1979) reported mouse-tomouse transmission of $S$. sebeki based on the following experiment. Sporocysts $(400,000)$ from owl no. 2 were fed to 3 A. sylvaticus; 8 days later 2 mice died, and the third mouse was euthanized. Schizonts (18 $\mu \mathrm{m}$ in diameter) were detected in smears of liver of all 3 mice; homogenate of livers of all 3 mice were inoculated intraperitoneally into 2 laboratory-bred $A$. sylvaticus. Several-centimeter-long macroscopic sarcocysts were found in skeletal muscles of both mice euthanized 4 mo later; only a few sarcocysts developed in these mice compared with heavy infections induced by feeding sporocysts. In the present study 
with $S$. strixi n. sp., schizonts were not identified, and sarcocysts were not detected in muscles of $\mathrm{KO}$ mice inoculated with liver homogenates of liver from acutely infected mice. Not all species of Sarcocystis are transmissible to KO mice. The parasite in the present study resembles $S$. neurona and $S$. speeri with respect to sporocyst infectivity; $S$. speeri forms sarcocysts in KO mice, but $S$. neurona does not (Dubey et al., 2016). The KO mice are considered an aberrant host for $S$. neurona because only schizonts are produced. In this respect, finding of sarcocysts in KO mice orally inoculated with sporocysts from barred owls is noteworthy and might assist in finding the natural intermediate host for $S$. strixi $\mathrm{n}$. sp. In a prey selection experiment (Graham, 2012), barred owls prefer small prey (Mus musculus) over larger prey (Rattus norvegicus or Rattus rattus); however, Hindmarch and Elliott (2015) documented no house mice (Mus musculus) in the diet (remains of 688 prey items) of barred owls inhabiting urban environments in the Lower Fraser Valley of southwestern British Columbia, Canada. Whether the house mouse is a natural host of $S$. strixi n. sp. needs investigation

Analysis of $18 S \operatorname{rRNA}, 28 S \operatorname{rRNA}$, and coxl sequences confirmed $S$. strixi n. sp. membership among the genus Sarcocystis. None of these 3 commonly used marker sequences were matched $100 \%$ with any sequence deposited in the GenBank. The $18 S$ rRNA sequences are mostly available in GenBank and commonly use in the differentiation of many species of Sarcocystis. However, the $18 S$ rRNA sequence of $S$. strixi n. sp. is $99 \%$ identical with many species of Sarcocystis: $S$. corvusi, S. lari, Sarcocystis sp. ex Phalacrocorax carbo, $S$ columbae, Sarcocystis sp. ex Columba livia, Sarcocystis sp. ex Anser albifrons, and many other species of Sarcocystis. In the phylogenetic analysis based on $18 S r R N A$ sequences, $S$. strixi $\mathrm{n}$. sp. clustered consistently in a separate clade. These high sequences identity indicated a close relationship with these species but a difference from them. The $28 S$ rRNA sequence of $S$. strixi n. sp. did not share the sequence identity more than $97 \%$ with any sequence deposited in the GenBank. The coxl sequences of $S$. strixi n. sp. shared the highest identity (99-98\%) with $S$. lutrae, $S$. turdusi, S. arctica, and S. speeri, S. rileyi, and $S$. neurona. The uses of coxl gene as a genetic marker for Sarcocystis species discrimination has been proposed recently, so presently only a limited number of sequences of coxl genes from different Sarcocystis are now available for comparisons (Gjerde, 2013). These data sufficed to conclude, however, that there were certain molecular and phenotypic characteristics (i.e., development of sarcocysts in $\mathrm{KO}$ mice and bearing a new type "type 1j" wall structure that does not change with age) that set them apart from other known species.

\section{ACKNOWLEDGMENTS}

This work was supported by grant 1505407 from the National Science Foundation Historically Black Colleges and Universities Undergraduate Program to A.R. von D. and an IRC grant from the Virginia-Maryland College of Veterinary Medicine to D.S.L. Mention of trade names or commercial products in this publication is solely for the purpose of providing specific information and does not imply recommendation or endorsement by the USDA; USDA is an equal opportunity provider and employer.

\section{LITERATURE CITED}

CAwThorn, R. J., AND R. J. BRoOKs. 1985. Light microscopical observations on sporogony of Sarcocystis rauschorum (Protozoa: Sarcocystidae) in snowy owls (Nyctea scandiaca). Canadian Journal of Zoology 63: 1455-1458.

Cawthorn, R. J., A. A. Gajadhar, and R. J. Brooks. 1984. Description of Sarcocystis rauschorum sp. n. (Protozoa: Sarcocystidae) with experimental cyclic transmission between varying lemmings (Dicrostonyx richardsoni) and snowy owls (Nyctea scandiaca). Canadian Journal of Zoology 62: 217225.

Cerná, Z. 1983. Multiplication of merozoites of Sarcocystis dispersa Cerná, Kolárová et Sulc, 1978 and Sarcocystis cernae Levine, 1977 in the blood stream of the intermediate host. Folia Parasitologica 30: 5-8.

Cerná, Z., I. Kolárová, And P. Šulc. 1978. Sarcocystis cernae Levine, 1977, excystation, life-cycle and comparison with other heteroxenous coccidians from rodents and birds. Folia Parasitologica 25: 201-207.

Dubey, J. P., R. Calero-Bernal, B. M. Rosenthal, C. A. Speer, AND R. FAYER. 2016. Sarcocystosis of animals and humans, 2nd ed. CRC Press, Boca Raton, Florida, 481 p.

Espinosa, R. H., M. C. Sterner, J. A. Blixt, and R. J. CAWTHORn. 1988. Description of a species of Sarcocystis (Apicomplexa: Sarcocystidae), a parasite of the northern sawwhet owl, Aegolius acadicus, and experimental transmission to deer mice Peromyscus maniculatus. Canadian Journal of Zoology 66: 2118-2121.

GJERde, B. 2013. Phylogenetic relationships among Sarcocystis species in cervids, cattle and sheep inferred from the mitochondrial cytochrome c oxidase subunit I gene. International Journal for Parasitology 43: 579-591.

GJeRde, B., AND T. D. Josefsen. 2015. Molecular characterisation of Sarcocystis lutrae n. sp. and Toxoplasma gondii from the musculature of two Eurasian otters (Lutra lutra) in Norway. Parasitology Research 114: 873-886.

Graham, S. A. 2012. Diet composition, niche and geographic characteristics, and prey size preference of Barred Owls (Strix varia) in the Pacific Northwest. M.S. Thesis. Boise State University, Boise, Idaho, $149 \mathrm{p}$

Guindon, S., J. F. Dufayard, V. Lefort, M. Anisimova, W. HordiJk, AND O. Gascuel. 2010. New algorithms and methods to estimate maximum-likelihood phylogenies: Assessing the performance of PhyML 3.0. Systematic Biology 59: $307-321$

Hindmarch, S., and J. E. Elliott. 2015. When owls go to town: The diet of urban barred owls. Journal of Raptor Research 49: $66-74$

Levine, N. D., ANd W. Tadros. 1980. Named species and hosts of Sarcocystis (Protozoa: Apicomplexa: Sarcocystidae). Systematic Parasitology 2: 41-59.

Munday, B. L. 1977. A species of Sarcocystis using owls as definitive hosts. Journal of Wildlife Diseases 13: 205-207.

Tadros, W., And J. J. LaARman. 1976. Sarcocystis and related coccidian parasites: A brief general review, together with a discussion on some biological aspects of their life cycles and a new proposal for their classification. Acta Leidensia 44: 1107. 
Tadros, W., And J. J. LaArman. 1978a. A comparative study of the light and electron microscopic structure of the walls of the muscle cysts of several species of Sarcocystid Eimeriid Coccidia (I). Proceedings of the Koninklijke Nederlandse Akademie van Wetenschappen, Amsterdam, series C 81: 469-491.

Tadros, W., AND J. J. LaARman. 1978b. Note on the specific designation of Sarcocystis putorii (Railliet \& Lucet, 1891) comb. nov. of the common European vole, Microtus arvalis. Proceedings of the Koninklijke Nederlandse Akademie van Wetenschappen, Amsterdam, Series C 81: 466-468.

TADros, W., AND J. J. LAARMAN. 1979. Successful rodent to rodent transmission of Sarcocystis sebeki by inoculation of precystic schizogonic stages. Transactions of the Royal Society of Tropical Medicine and Hygiene 73: 350-351.
Tadros, W., And J. J. LaArman. 1980. The tawny owl, Strix aluco as final host of a new species of Sarcocystis with Mus musculus as intermediate host. Tropical and Geographical Medicine 32: 364.

Tadros, W., and J. J. LaArman. 1982. Current concepts on the biology, evolution and taxonomy of tissue cyst-forming eimeriid coccidia. Advances in Parasitology 20: 293-496.

Verma, S. K., D. A. Rosypal Von Dohlen, J. D. Mowery, D. Scott, B. M. Rosenthal, J. P. Dubey, and D. S. Lindsay. 2017. Sarcocystis jamaicensis, n. sp. from red-tailed hawks (Buteo jamaicensis) definitive host and IFN-gamma gene knockout mice as experimental intermediate host. Journal of Parasitology 103: 555-564. 